\title{
Ergonomic considerations in school environments - the need for widening the scope
}

\author{
Kapila Jayaratne $\mathrm{a}^{\mathrm{a},}$ \\ ${ }^{a}$ Maternal and Child Morbidity and Mortality Surveillance Unit, Family Health Bureau, Ministry of Health, 231 \\ De Saram Place Colombo 10, Sri Lanka
}

\begin{abstract}
Behaviour patterns specific to children pose them at greater risk of environmental hazards than adults. Ergonomics is the science of matching human interaction with the proximate environment. Conventionally ergonomic principles were applied on adult work places to ensure safety of the working environment. With emerging scientific evidence, school environments are being a focus to apply ergonomic principles. Children spend more time within schools during critical developmental stages of their life. Everybody feels that the schools are safe places, but they are not. A multitude of ergonomic hazards have been identified in school settings. Widespread mismatches between anthropometry and school furniture, heavy schoolbag carriage and unhealthy bag behaviour are significant. Negative effects range from general tiredness, musculoskeletal pains, spinal deviations, shoulder level shifts, injuries and psychological disturbances. There are fragmented efforts to widen ergonomic concepts to health care professionals and other stakeholders of child health. Addressing ergonomic issues will ensure that children, the future productive generation contributing to economic growth and development of a country, are provided with opportunities in a healthy environment. This paper emphasizes the need for a concerted effort on widening the scope of ergonomics to cater for the evolving demand.
\end{abstract}

Keywords: school, ergonomics, educational environment

*Corresponding authors. E-mail: kapjay613@gmail.com 


\section{Introduction}

Children are not smaller versions of adults. Behaviour patterns specific to children pose them at greater risk of environmental hazards than adults. Investing in children's health is a valuable economic investment [1].

Ergonomics is the science of matching human interaction with the proximate environment. Conventionally ergonomic principles were applied on adult work places to ensure safety of the working environment. With emerging scientific evidence, child environments are being a focus to apply ergonomic principles.

The school environment has a strong impact on children's health since they spend much of the daytime within schools during critical developmental stages of their life. Everybody feels that the schools are safe places, but they are not. Distinct behaviour patterns of children pose them at greater risk of environmental hazards than adults. In fact, the school is the working place of children.

\section{Emerging global evidence}

Evidence pool of ergonomics of children is widening. A multitude of ergonomic hazards have been identified in school settings. The issues include incompatibilities of immediate environmental parameters such as the seating, desk, carriage of school books, position of the blackboard and the surrounding atmosphere (lighting, sounds, vibration and ventilation) with child human factors. Research evidence shows widespread mismatches between student body sizes and desks and chairs. Heavy schoolbag carriage and unhealthy bag behaviour are significant. The negative effects range from general tiredness, musculoskeletal pains, spinal deviations, shoulder level shifts, injuries and even psychological disturbances [3-6]

\section{Widening the scope of ergonomics}

Traditional ergonomics focused mainly on adult environments especially in factories, office environments and other work places. Introduction of ergonomics at the school, the "work place" of children, is no exception to this. School has identified as an effective setting for health promotion. With the introduction of "Health Promoting Schools", WHO has
Even with the continuing revelations of ergonomic risks and negative health consequences, ergonomic concepts have not yet reached majority of health care professionals and other stakeholders of child health. The International Ergonomic Association is committed to elaborate and advance ergonomics science and practice, and to improve the quality of life by expanding its scope of application and contribution to society. There are fragmented efforts in few countries addressing the ergonomic demand of children. Even the recently published World Health Organization (WHO) Guidance and Resources for Establishing on Children's Environmental Health Centres does not include ergonomic hazards [2].

There is an unmet need of widening the scope of ergonomics as well as health sector (both curative and preventive) contribution to cater for the child ergonomic issues.

provided an opportunity to ensure a safe environment for school children. With a classical ergonomic approach, solutions to health and safety problems in the school environments could be addressed with an understanding of the interaction between children and ergonomic parameters. This will ensure that the school environment is safe for its working population -the children. Success stories are numerous in the integration of ergonomics in school health promotion.

Many initiatives are underway addressing child ergonomic issues. Several industrially developed countries have focused on ergonomics in school environments [7-12]. In addition to addressing microergonomics issues such as mismatch between student body sizes and their desks and chairs, the schoolbag carriage and the musculoskeletal disorder prevalence, they are now focusing on macro-ergonomic issues [11]. Although there is a big question mark on how to translate such lesions in to practice in other countries, especially in resource-poor contexts, a few developing countries have contemplated on addressing even micro-ergonomics issues [13]. More than two thirds of the children in the world live in developing countries and they are the most at risk population on environmental hazards. Children in industrially developing countries may carry a disproportionately heavy share of the morbidity due to mismatched ergonomics. 
Role of health providers in ergonomics for children is of paramount importance. Usually health professionals take the lead role in initiating programs on environmental healt, only because lack of expertise in non-health stake holders. A mechanism to bring all agencies addressing various parameters of child ergonomic issues has to be worked out. Health care professionals and other stakeholders of child health have to update their knowledge on ergonomic risks of children and consequences to model clinical management protocols and prevention.Usually non-health partners fail to synchronize with pace of the healthcare system. A mapping of probable stake holders would be beneficial. Then comes the ownership issue -health-led vs non-health-led. These issues have fundamental implications on funding, implementation and sustainability of school ergonomic promoting programs in any context.

\section{Available entry-points}

There are ample entry points with which integration of ergonomics in child environmental settings could be made a reality. WHO is also creating networks and alliances for the successful implementation of health-promoting schools concept[14].

The International Ergonomic Association (IEA) can assume the lead role in a world-wide collaborative initiative to concentrate on this issue with the leading stakeholders. In a context of addressing macro-ergonomic issues in ergonomics in schools [11], an IEA lead effort could cover wider aspects of macro-ergonomics such as learning environments, ergonomics pedagogy and curriculum content/structure at national levels in liaison with both Ministries of Education and Health. As such exploration in to such opportunities and effective partnership building will undoubtedly help in the improvement of ergonomics in child environments in the entire world. WHO, World Bank, UNICEF, United Nations Educational, Scientific and Cultural Organization (UNESCO), Education Development Center, Partnership for Child Development and Education International in partnership have launched an initiative to ensure that positive changes in a school's physical environment are supported, reinforced and sustained.

Partnership formation with leading organizations concerned with child health would be a starting point followed up with role identification and funding.

\section{Discussion}

Ergonomics optimise human well-being and overall system performance. School system will undoubtedly revolutionize with incorporation of ergonomics in health promotion strategies. Facilitation of organizational structure for the empowerment of school children to act in and promote healthy ways will ensure a productive future generations. A multi-prong action is required to ensure ergonomically safer environments for children worldwide. It necessitates concerted efforts of both international and national level stakeholders of child health using strategies that are feasible and available, capitalizing on existing frameworks and infrastructure and innovative approaches.

Addressing ergonomic hazards in educational settings will ensure that children, the future productive generation contributing to economic growth and development of a country, are provided with opportunities for education in a healthy environment.

\section{References}

[1] Bearer, C. F. (1995). "Environmental health hazards: how children are different from adults." Future Child 5(2): 11-26.

[2] World Health Organization (2010). Guidance and Resources for Establishing on Children's Environmental Health Centres

[3] Harreby, M, Nygaard, B, Jessen, T, Larsen, E, StorrPaulsen, A, Lindahl, A, Fisker, I. and Laegaard, E. (1999) Risk factors for low back pain in a cohort of 1389 Danish school children: an epidemiologic study. European Spine Journal, 8, 444-450.

[4] Negrini S, Carabalona R, Sibila P. (1999).Backpack as a daily load for schoolchildren. Lancet;354:1974.

[5] Szpalski M, Gunzburg R, Balagué F, Nordin M, Mélot C. (2002). A 2-year prospective longitudinal study on low back pain in primary school children. European Spine Journal 11: 459-464.

[6] Viry P, Creveuil C, Marcelli C. (1999). Nonspecific back pain in children: a search for associated factors in 14 year old schoolchildren. Rev Rhum Engl Ed ;66:381-8.

[7] Barrero, M. and A. Hedge. School Ergonomics Programs: Guidelines for Parents 2000 [cited 200915 th April ]; Available from: http://ergo.human.cornell.edu/MBergo/intro.html.

[8] Whittfield, J.K., S.J. Legg, and D.I. Hedderley, The weight and use of schoolbags in New Zealand secondary schools. Ergonomics, 2001. 44(9): p. 819-24.

[9] Breithecker D, More health and well-being in the "school as place of work" -a Project Report. 2005, Federal Working Group on the Development of Posture and Exercise. 
[10] Heyman, E. and H. Dekel, Ergonomics for children: an educational program for elementary school. Work, 2008. 31(2): p. 253-7.

[11] Legg, S. and K. Jacobs, Ergonomics for schools. Work: A Journal of Prevention, Assessment and Rehabilitation, 2008. 31(4): p. 489-493.

[12] Lueder, R. and V.B. Rice, eds. Ergonomics for children - Designing products \& places for toddlers to teens. 2008, Taylor \& Francis: London \& New York.

[13] Jayaratne, I.L.K., D.N. Fernando, and J.M.J.S.K. Jayanetti, Prevalence of musculoskeletal pain and con- tributory factors among school-going early adolescents, in Postgraduate Institute of Medicine. 2007, University of Colombo: Colombo.

[14] World Health Organization, Promoting Health through Schools: a summary and recommendations of WHO's Expert Committee on Comprehensive School Health Education and Promotion., in WHO Technical Report Series. 1996. p. 1-93. 